\title{
Evaluation of Wireless Control System of Water Pump Station
}

\author{
Elsanosy M. Elamin \\ Electrical Engineering Department, Faculty of Engineering, University of Kordofan, Sudan. \\ esanosy@hotmail.com
}

\begin{abstract}
The systems are now generally deploying rapidly in their both quality and quantity to meet the current requirements of the development. The running operating expenses are also increasing proportionally to the system sophisticated. Therefore, the aided tools are required to assist in reducing the overall expenses versus the total throughput. The wireless remote control is used as aided tool. The paper discusses the impact of expansion levels of remote control on the water pump station. The wireless control levels are applied gradually and consequently the impact is evaluated. The cost decreased as the wireless control levels in creased. The wireless control system can be trusty used to facilitate and reduce both the operating time and cost.
\end{abstract}

Keywords: control levels, decoders, devices, cost reduction

\section{INTRODUCTION}

The water pump station was operated manually because of locating in far spacing positions. So, it required to be controlled according to the need of water size as a maximum throughput. Therefore, the control process can be carried out remotely to assist in reducing the operating time and cost when high demand. The paper illustrates the way exploiting the wireless control system and its impact on the station as overall operating time and cost reduction when applying the wireless control levels gradually. The station is working 24 hours a day to provide a continuous supply of water. The working team is divided into three equal qualified shifts. Each one is consists of 6 engineers and 24 technicians when the station performing the full capacity. The overall team members of all shifts are 90 members. The water pump station is composed of 95 water pumps to be switched on/off according to the need.

\section{THE WIRELESS CONTROL SYSTEM}

Is used to reduce the working team members at each shift.The key factor in expanding this system into multi-different levels is the decoders that are shown in the table 1[1],[2].

Table1. Shows the decoders used in expansion controlled devices

\begin{tabular}{|c|c|c|}
\hline Decoder Type & No of Decoders & No of Controlled Devices \\
\hline $1: 2$ & 7 & 14 \\
\hline $2: 4$ & 6 & 24 \\
\hline $3: 8$ & 5 & 40 \\
\hline $4: 16$ & 4 & 64 \\
\hline $5: 32$ & 3 & 96 \\
\hline
\end{tabular}

The beating heart of selecting devices according to the pre-defined scenario is the Microcontroller. The team member has to enter a controlling value related to the controlled pump remotely through cell phone1 (MS1) via wireless network to the GSM Modem as shown in figure 1. The controlling signal is generated by the remote user who carries MS1 in all the wireless coverage area to assure all the required security features such as authentication, integrity, and ciphering. The controlling signal is captured by the GSM Modem that attached to the Microcontroller. The Microcontroller react to the incoming controlling signal and processed to provide an appropriate decision to switch the relevant pump. Selecting the relevant pump is depending upon the addressing by 5:32 decoders. Three pieces of 5:32 decoderscan easily build the interface network to directly control the 96 devices but the system consists of 95 pumps. Each 5:32 decoder is controlled by the Enable terminal (É) [1], [3]. The Enable terminal is generated from microcontroller output which is in high level of logic.The HCF4069 is exploited to invert the high level of logic into low to enable 5:32 decoders. 


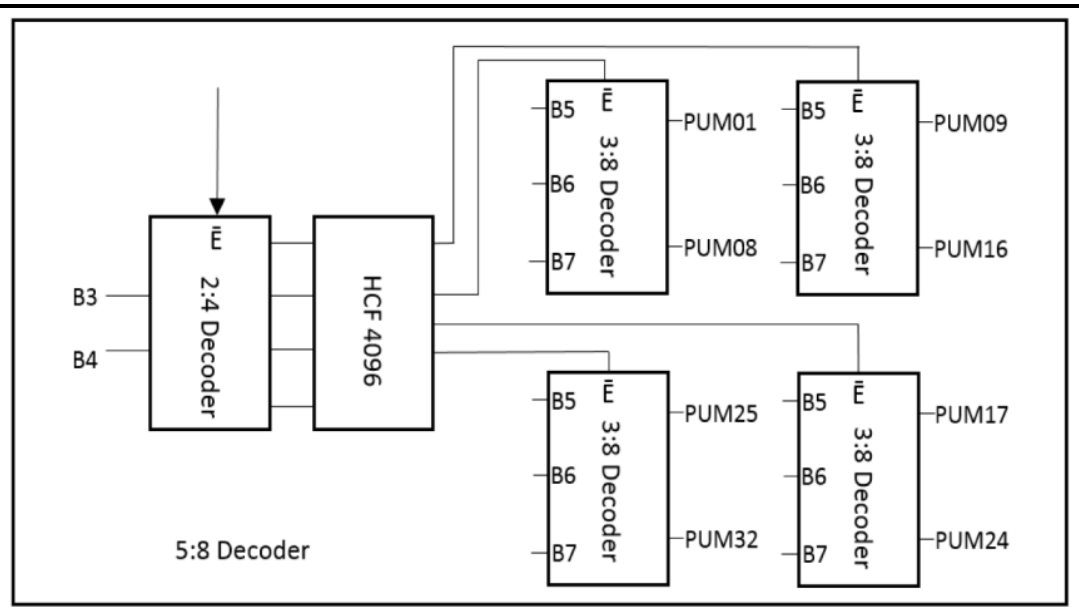

Figure1. Shows the 5:32 Decoder Circuit

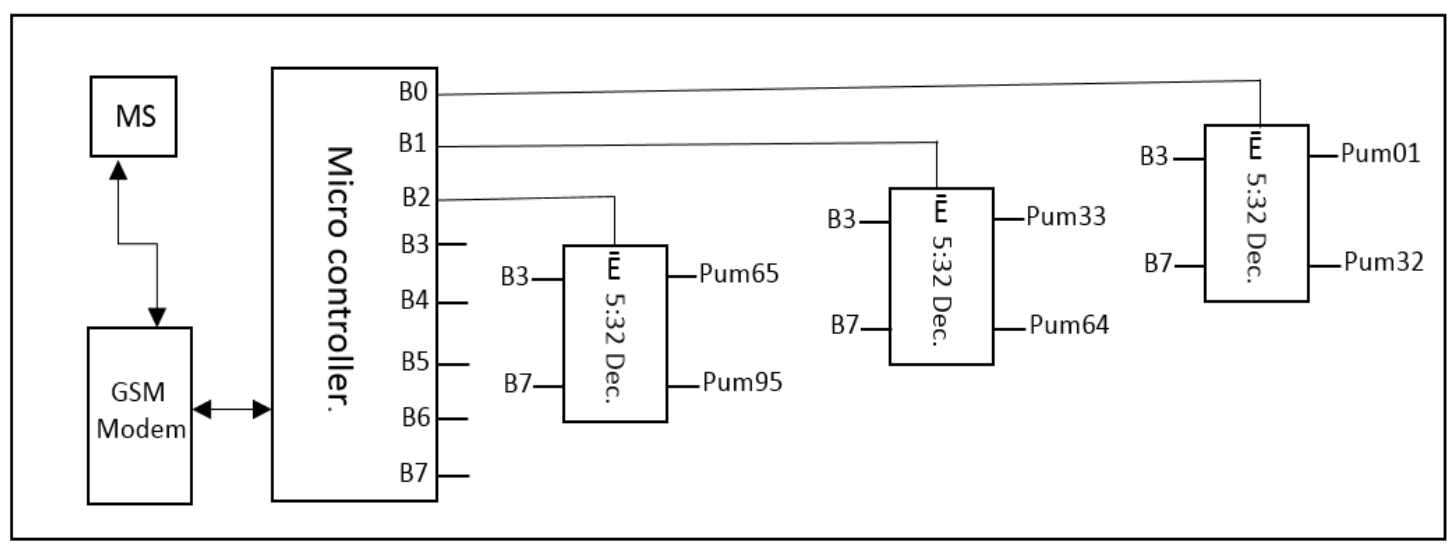

Fig2. Illustrates the maximum expansion level of wireless control [4]

\section{Water Pump Station}

It established to provide a continuous water stream and operated under supervision of qualified shifts. Every working shift team members is formed of three engineers and 12 technicians for each mechanical and electrical department as shown in table 2 below [5],[6].

Table2. Shows the team members per a shift

\begin{tabular}{|c|c|c|}
\hline & Mechanical & Electrical \\
\hline Engineers & 3 & 3 \\
\hline Technicians & 12 & 12 \\
\hline
\end{tabular}

Now, the remote control system is gradually applied to the station. As a result, there is a number of left members from each shift as shown in table 3. The number of left members (LM) can be calculated as equation 1

$L M=\frac{(\text { No of Controlled Devices })(\text { Overall Team Memnbers }) \times 0.75}{(\text { Max No of Devices })}$

Table3. Shows the number of left members for three shifts versus applied expansion level

\begin{tabular}{|c|c|c|}
\hline No of Controlled Devices & left members (\%) & No of the Left members \\
\hline 14 & 11 & 9 \\
\hline 24 & 19 & $17 \approx 18$ \\
\hline 40 & 32 & $28 \approx 27$ \\
\hline 64 & 51 & 45 \\
\hline 96 & 75 & $67 \approx 66$ \\
\hline
\end{tabular}

The total number of the left members is distributed among the three different departments depending upon the criterion that for every left engineer there are also four technicians are left. The number of left members in table 3 is approximated to comply with the aforementioned criterion. Table4 illustrate the distribution of both working and left members per shift relating to the different levels of the wireless control system when applied. 
Evaluation of Wireless Control System of Water Pump Station

Table4. Shows the left team members/shift when the wireless control levels applied

\begin{tabular}{|c|c|c|c|c|c|c|c|}
\hline \multirow[t]{2}{*}{$11 \%$} & \multicolumn{2}{|c|}{ Working Members } & \multirow{2}{*}{$\begin{array}{l}\text { Left } \\
\text { Mem. }\end{array}$} & \multirow[t]{2}{*}{$19 \%$} & \multicolumn{2}{|c|}{ Working Members } & \multirow[t]{2}{*}{ Left Mem } \\
\hline & Mech & Elect. & & & Mech & Elect. & \\
\hline Eng. & 3 & 3 & 0 & Eng. & 3 & 2 & 1 \\
\hline Tech. & 11 & 10 & 3 & Tech. & 10 & 9 & 5 \\
\hline Total & 14 & 14 & 3 & Total & 13 & 11 & 6 \\
\hline \multirow[t]{2}{*}{$32 \%$} & \multicolumn{2}{|c|}{ Working Members } & Left & $51 \%$ & \multicolumn{2}{|c|}{ Working Members } & Left Mem. \\
\hline & Mech & Elect. & Mem. & & Mech & Elect. & \\
\hline Eng. & 2 & 2 & 2 & Eng. & 2 & 1 & 3 \\
\hline Tech. & 8 & 9 & 7 & Tech. & 6 & 6 & 12 \\
\hline Total & 10 & 11 & 9 & Total & 8 & 7 & 15 \\
\hline \multirow[t]{2}{*}{$75 \%$} & \multicolumn{2}{|c|}{ Working Members } & Left & & & & \\
\hline & Mech & Elect. & Mem. & & & & \\
\hline Eng. & 1 & 1 & 4 & & & & \\
\hline Tech. & 3 & 3 & 18 & & & & \\
\hline Total & 4 & 4 & 22 & & & & \\
\hline
\end{tabular}

\section{THE RESUlts}

The main cost that is been evaluated is the total payment to working members according to the fact that the cost of four technicians is equal to the one engineer cost. So, the overall cost of 18 engineers and 72 technicians is equal to the cost of 147 technicians. Table 5 shows the total cost reduction when applying the wireless control system. It is found that the wireless control system has a great cost reduction of $48.97 \%$ and $81.6 \%$ when it applied to $67 \%$ and $100 \%$ of the pumps respectively. The number of left members below the $67 \%$ has no great influence because of consisting of technicians rather than engineers.

Table5. Shows the total cost reduction versus the total left members

\begin{tabular}{|c|c|c|c|c|}
\hline \multirow{2}{*}{ Controlled Devices (\%) } & \multicolumn{3}{|c|}{ Left members } & \multirow{2}{*}{ Cost reduction (\%) } \\
\cline { 2 - 4 } & Engineers & Technicians & Total & $\mathbf{6 . 1 2}$ \\
\hline 14 & 0 & 9 & 9 & 18 \\
\hline 25 & 3 & 15 & 27 & $\mathbf{3 0 . 3 6}$ \\
\hline 42 & 6 & 21 & 45 & $\mathbf{4 8 . 9 7}$ \\
\hline 67 & 9 & 36 & 66 & $\mathbf{8 1 . 6}$ \\
\hline 100 & 12 & 54 & 9 \\
\hline
\end{tabular}

Both fig 2 and 3shows the relationship between controlled devices and both left members and cost reduction. It is clearly that wireless control system is affect greatly on the station in reducing the working team members for each shift especially at full wireless control. As a result, the payment for the working members is also reduced.

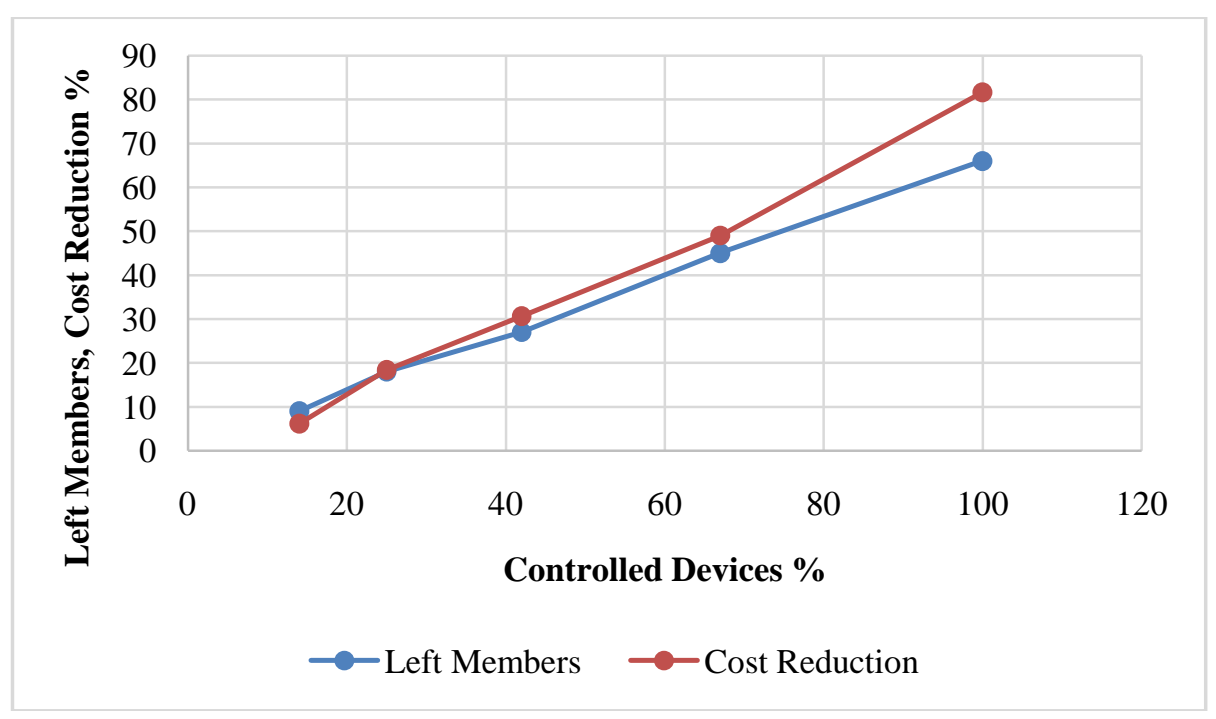

Figure2. The controlled devices versus left members and cost reduction 


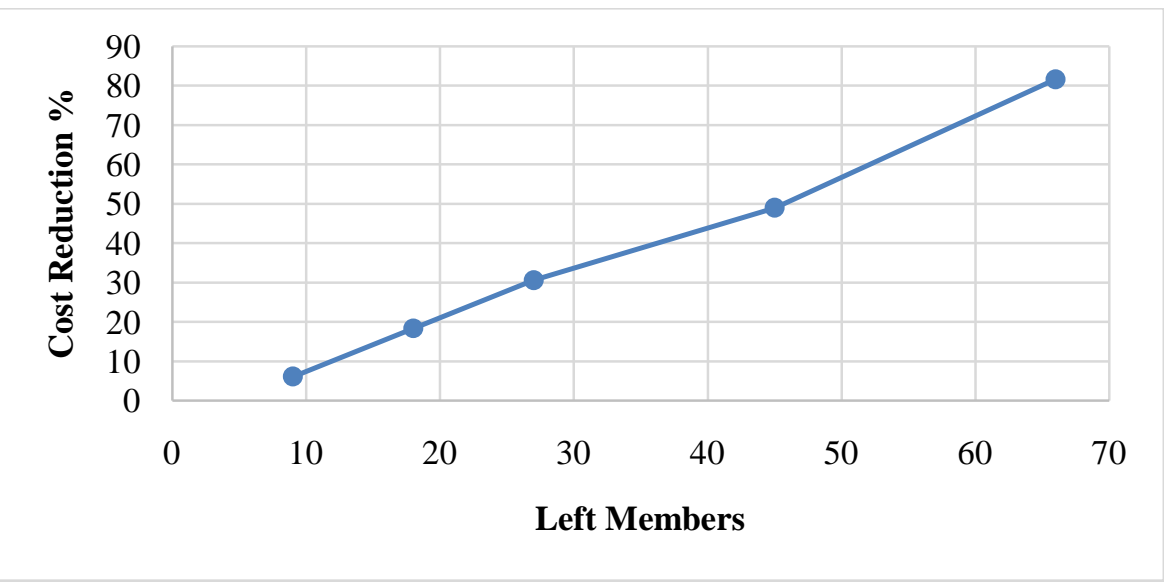

Figure3. Left members versus cost reduction

\section{Conclusion}

The wireless control system is applied gradually and it is impact is evaluated. Its impact shows the feasibility of using such systems especially the complicated one. The study focused only on the cost of member's payment. Also the system can be re-evaluated for running, maintenance, and capital cost for different cases to show the great impact at which case or to compromise among them.

\section{REFERENCES}

[1] Elsanosy M. Elamin, Murtada M. Abdelwahab, Abdelrasoul J. Alzubaidi, Wireless Secured Remote Control System Expansion, IOSR Journal of Engineering, 5(1), V3, PP 48-5,Jan. 2015.

[2] Elsanosy M. Elamin, Zohair M. E. Husein, Abdelrasoul J. Alzubaidi, "CDMA Based Secured Dual Gain Control of Helical Feed Parabolic Reflector Antenna", IJEEE International Journal of Electrical and Electronics Engineers, Vol. 7 Issue 2, PP(257-263) July- December 2015, ICSTM15

[3] Elsanosy M. Elamin, Abdelrasoul J. Alzubaidi, Secured Remote Switching DC Motors, IOSR Journal of Engineering IOSRJEN, 3(12), Dec. 2013, 7-10.

[4] Robert L. S, George T. N, Pumping Station Design, Butterworth-Hieinmann, Montana, 1998.

[5] Elsanosy M. Elamin, Zohair M. E. Husein, The Maximum Expansion level of the Secured Remote Control System, IJEEE International Journal of Electrical and Electronics Engineers, Vol. 8 Issue 1, PP(132-136) January- June 2016.

[6] Hubbel R. C, Pump Station Maintenance, YCUA, 2012.

\section{AUTHOR's BIOGRAPHY}

Dr. Elsanosy M. Elamin, Obtained his BSc in Electrical and Computer Engineering at Omdurman Islamin University 1999. Received his MSc. In Communication at Karary Academy of Technology 2003 and Ph.D. in Electronics at Sudan Academy of Sciences 2014. Assistant Professor and head department of electrical engineering, University of Kordofan. His field interest is in Electronic Design, Data Communication Networks, and Mobile Communication Networks. 